\section{VIVIENDAS DE MADERA CON ELEVADO NIVEL DE PREFABRICACION EN SUECIA}

\section{P. Díaz-Romeral}

124-32

A prefabricación de viviendas de madera en L Suecia es una rama importante de la industria del país, donde existen abundantes recursos de madera - material excelente para construir-, una tradición en la construcción en madera y una industria de serrería pujante que ofrece un adecuado marco para su desarrollo.

Por otro lado es conocido mundialmente el elevado nivel de la tecnología sueca, que se aplica en todas sus modalidades en la producción de este tipo de viviendas de gran aceptación entre la población.

\section{Métodos de producción}

Los métodos de producción de viviendas de madera pueden dividirse en tradicionales e industriales. El método tradicional de edificación in situ se caracteriza por una alta proporción de trabajo hecho en el lugar y bajo nivel de prefabricación de los materiales empleados. La construcción industrial utiliza métodos que incluyen fundamentalmente en la instalación de componentes del edificio, elementos y unidades de construcción prefabricados en lugar de los ejecutados en obra.

En la actualidad, la construcción de viviendas de madera en Suecia, en su práctica totalidad, se Ileva

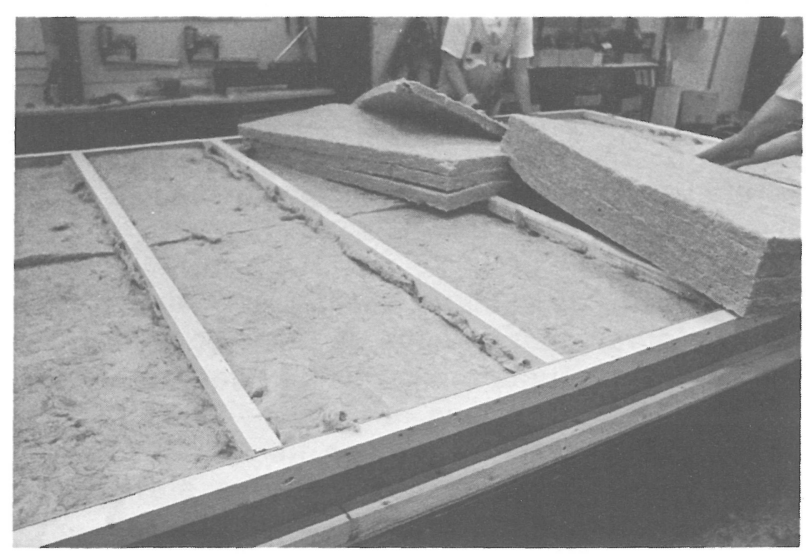

a cabo mediante la utilización de métodos industriales en diferentes grados. Con el avance en las condiciones para la producción industrial de viviviendas puede deducirse: que la prefabricación en madera seguirá creciendo en los próximos años en la misma dirección en que lo ha hecho en todos los países escandinavos.

Los métodos industriales empleados en la construcción de viviendas unifamiliares de madera, pueden dividirse en:

- Sistema de pequeños elementos panelizados.

- Sistema de grandes elementos panelizados.

- Sistema de "Unidades-caja".

- Sistema de entramado.

- Sistemas auxiliares.

\section{Sistema de pequeños elementos panelizados}

Este método se basa en el empleo de paneles que pueden ser movilizados por dos hombres.

Las paredes exteriores tienen como anchura máxima los dos metros; normalmente son de 60, 120 y $180 \mathrm{~cm}$ y de altura correspondiente a un piso. Las dimensiones de los diferentes elementos que componen los cerramientos permiten la construcción de diferentes fachadas. En fábrica se producen los armazones de cubierta (normalmente cerchas de madera) y los elementos auxiliares. Los elementos complementarios de construcción son normalmente paneles semielaborados y piezas de madera. El método se presta a la autoconstrucción por el propio usuario con la ayuda de pequeños constructores y es cuantitativamente una parte importante en este tipo de viviendas, ya que el precio de los componentes producidos en fábrica representa aproximadamente entre el $25 \%$ y el $32 \%$ del coste global de la vivienda, representando el montaje entre un $4 \%-6 \%$ del precio final.

\section{Sistema de grandes elementos panelizados}

El principio esencial de este sistema se basa en que las paredes de cerramiento, tabiques de división, los forjados y cubiertas están formados por elementos con dimensiones cercanas a los 2 metros.

Los forjados normales y de cubierta son elementos en madera, de anchura $120 \mathrm{~cm}$.

El método exige normalmente el empleo de grúas. 

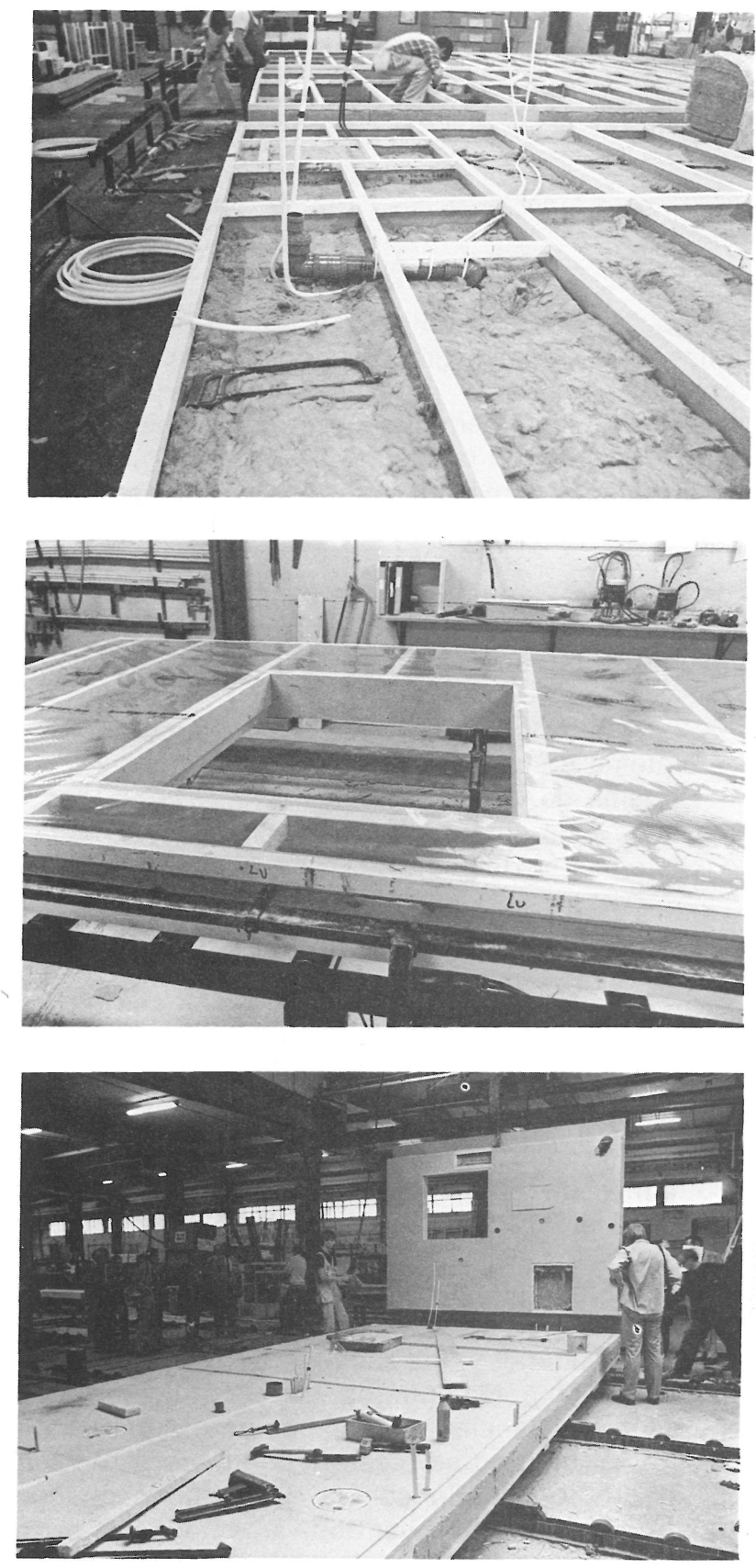

El porcentaje del costo del edificio que representan los componentes industriales se sitúa entre el 36-42 por ciento, suponiendo el coste de los trabajos de montaje una parte pequeña, menor que en el caso de elementos pequeños, del orden del $2-4 \%$.

\section{Sistema de «unidades-caja»}

El sistema se basa en la fabricación de volúmenes que forman parte de la vivienda.

Las dimensiones de las unidades-caja tienen limites debido a aspectos de transporte, siendo normalmente de anchura $2,40 \mathrm{~m}$, dependiendo su longitud del tipo de vivienda.
El coste de producción de los elementos industriales alcanza el 60-70 \% del total de la vivienda, ya que normalmente incorpora las instalaciones de calefacción y electricidad; las conexiones para el suministro de agua y evacuación se realizan en obra.

La distancia considerada normalmente como rentable para su transporte se cifra en 150 - $200 \mathrm{~km}$.

\section{Sistemas de entramado}

Estos sistemas se caracterizan porque el armazón se compone de pies derechos y vigas de madera, sobre los que se disponen los cerramientos y forjados de suelo y cubierta, también de madera.

Los elementos normales para forjados suelen tener dimensiones de $240 \times 480 \mathrm{~cm}$ y las paredes de cerramiento de altura de un piso suelen tener una anchura de $240 \mathrm{~cm}$.

\section{Sistemas auxiliares}

Son métodos de producción basados en el uso de elementos de madera de dimensiones fijas.

El sistema se aplica con frecuencia como complemento a los diferentes sistemas completos de construcción, y tiene la ventaja de que el método permite minimizar los costes de transporte, con la desventaja de emplear un bajo nivel de prefabricación.

\section{Sistema constructivo de una vivienda de madera}

\section{Cubierta, estructuras y materiales}

La mayor parte de las viviendas se basa en el principio de la cubierta inclinada, aunque también se construyen cubiertas planas.

Los materiales de cobertura son fundamentalmente tejas en el caso de cubierta inclinada, aunque también se utilizan diferentes tipos de filtros impermeabilizantes, y placas de cemento o asbesto.

El tablero de la cubierta es casi sin excepción de elementos machiembrados, clavados 0 encolados de madera y tableros de piezas de madera laminada.

La estructura de cubierta consta, normalmente, de cerchas atirantadas o vigas de madera; también se emplean estructuras mixtas de paneles de particulas y madera laminada formando elementos estructurales complejos, que con frecuencia incorporan el aislamiento térmico, y cuyo sistema de unión está formado por anclajes mecánicos. 
Las cargas de viento y nieve que soportan las cubiertas varían de acuerdo con las condiciones geográficas, oscilando entre $100 \mathrm{~kg} / \mathrm{m} .{ }^{2}$ hasta 300 $\mathrm{kg} / \mathrm{m}^{2}{ }^{2}$ en caso de nieve.

El bajo peso de las estructuras de madera es una ventaja para su transporte e instalación, pero exige un cuidado diseño, y cálculo.

\section{Cerramientos}

El espesor de los cerramientos exteriores de una vivienda unifamiliar de madera está generalmente más condicionado por la cantidad de aislamiento térmico utilizado que por las cargas que soporta, que son de pequeña consideración.

La estructura exterior está formada por elementos de madera de $50 \times 100 \mathrm{~mm}$ (piés derechos), sobre los que se clavan paneles de madera, incorporando el aislamiento térmico; el acabado exterior suele consistir en piezas de madera solapadas y clavadas, con terminación de pintura especial antihumedad.

La superficie interior del cerramiento es con frecuencia un tablero de partículas de $12 \mathrm{~mm}$ de espesor, aplicándose sobre las juntas una banda elástica mediante un adhesivo apropiado, de forma que los paramentos queden perfectamente preparados para recibir el papel de terminación.

En Suecia la temperatura puede oscilar entre $30{ }^{\circ} \mathrm{C}$ y $-30^{\circ} \mathrm{C}$, esta fluctuación (especialmente en las temperaturas inferiores a $0^{\circ} \mathrm{C}$ ) exige un estricto comportamiento aislante del cerramiento.

La humedad, en estas condiciones de baja temperatura que se prolonga durante varios meses al año, tiende a desplazarse de forma continuada, desde el aire dentro de la habitación a través del muro, hacia la superficie exterior, con vistas a prevenir este pernicioso efecto que aumenta el coeficiente de conductividad; disminuyendo su capacidad de aislamiento, se instala una barrera de vapor bajo la superficie de los paneles que integran el muro de cerramiento, y por la cara interior del aislamiento térmico, el material más frecuentemente utilizado son las láminas plásticas.

La protección contra el viento (infiltraciones) se coloca en la superficie exterior del aislamiento térmico, con el fin de prevenir el movimiento libre del aire dentro de las capas de aislamiento térmico de la pared.

En las edificaciones de madera actuales se utilizan normalmente como elementos de protección frente al viento los tableros porosos de partículas o fibras. La superficie exterior del muro también a veces se reviste con paramentos de ladrillo.
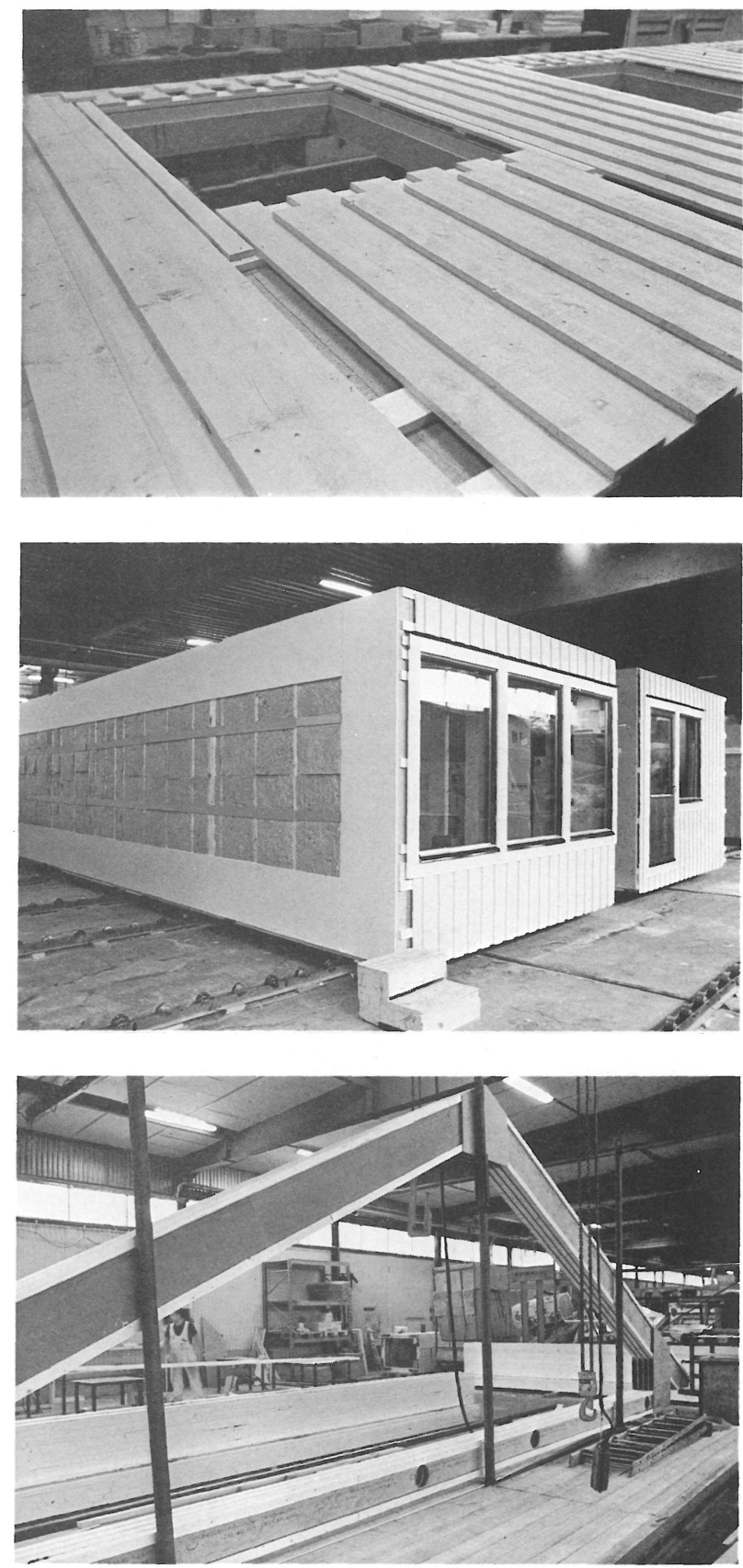

Suelen practicarse ranuras de ventilación de espesor entre 2 y $5 \mathrm{~cm}$ en el seno del muro para eliminar la humedad que pudiera penetrar en el muro desde el exterior, aspecto considerado muy importante en su conservación.

En la parte baja del cerramiento, en la zona en que se apoya sobre el forjado de suelo, se lleva a cabo la colocación de aislamiento térmico con el fin de eliminar eventuales puentes térmicos; la madera en esta zona de apoyo es revestida con una imprimación impermeabilizante; también se toman medidas especiales en la parte superior del muro que soporta las cargas de la estructura de madera de cubierta. 


\section{Forjados}

El tipo predominante de forjado consiste en un suelo aislado compuesto como se indica a continuación:

- Encachado de $20 \mathrm{~cm}$ aproximadamente.

- Solera de hormigón de 10-15 cm.

- Aislamiento térmico de poliestireno $(10 \mathrm{~cm} \mathrm{o}$ lana mineral).

- Barrera de vapor.

- Superficie de suelo (normalmente un tablero de partículas).

También es frecuente colocar los forjados construidos con viguetas en madera, sobre una cámara de aire de $1 \mathrm{~m}$ de altura aproximadamente.

\section{Aislamiento térmico y calefacción}

Para obtener subvenciones estatales a la construcción es necesario que el aislamiento térmico empleado cumpla determinados requisitos, que normalmente se cumplen instalando $150 \mathrm{~mm}$ de lana mineral en los cerramientos, y placas de $250 \mathrm{~mm}$ como aislamiento de cubierta en las viviendas unifamiliares.

Debido al incremento en los costes de la energía, se ha apreciado como económicamente preferible construir con estos espesores medios, más gruesos que con anterioridad.

La mayor parte de las viviendas unifamiliares tienen en Suecia su propia caldera de calefacción. normalmente utilizando combustibles liquidos.

En la actualidad se han vuelto a emplear sistemas abandonados en zonas urbanas o agrupaciones de viviendas unifamiliares; estos sistemas utilizan la energía de las plantas térmicas para calefacción.

La energía eléctrica está también bastante extendida como sistema de calefacción basado en el uso de la carga eléctrica nocturna; un tanque de agua caliente es calefactado durante la noche y el calor es liberado durante el día a través de los radiadores del edificio.

\section{publicaciones del I.E.T.C.C.}

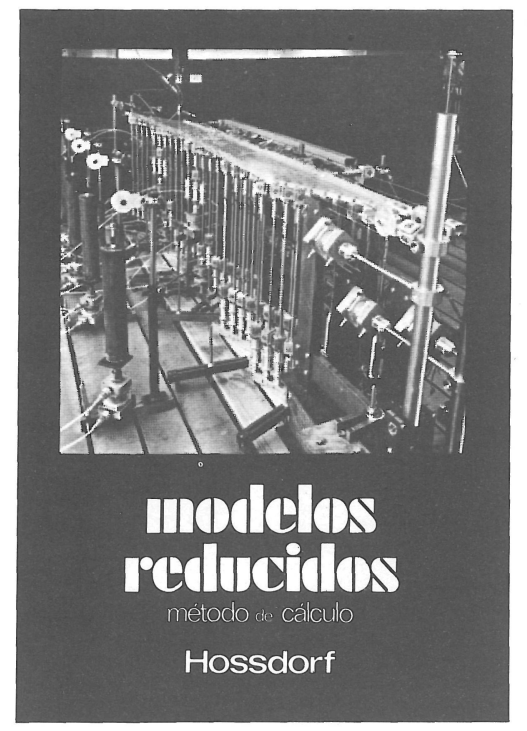

Modelos reducidos. Método de cálculo

H. Hossdorf, Ingeniero Civil

La técnica de los ensayos en modelos reducidos de estructuras sufre hoy dia una decisiva metamorfosis. Hasta hace poco era un medio más bien de artesanía, que no siempre era tomado en serio por los academicos teorizantes Dara comprender el comportamiento resistente de las estructuras complejas y a que se acudió las más de las veces, como a un ultimo remedio debido a sus indiscutibles insu cias. Sin embargo, en poco tiempo y gracias a su conexión con los ordenadores digitales, se ha transormado en un instrumento científicamente valioso. que no puede quedar a un lado en la práctica diaria del Ingeniero Proyectista.

Un volumen encuadernado en cartoné plastificado con lomo de tela, de $17 \times 24 \mathrm{~cm}$, compuesto de 250 páginas, 158 figuras y fotografias.

Precios: 1.800 ptas.; \$ USA 26.00

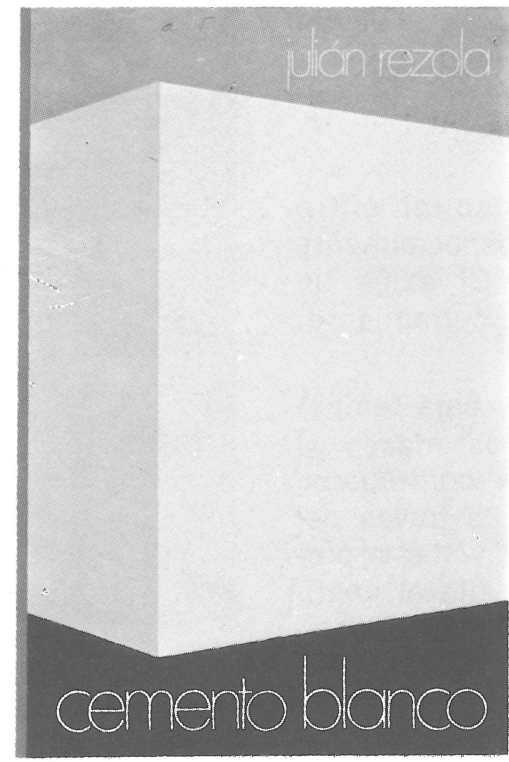

Cemento blanco

Julián Rezola

Ingeniero Químico Dipl. I. Q. S.

Sabido es que existe una extensa y documentada bibliografía sobre el cemento gris: en cambio, no puede decirse lo mismo acerca del cemento portlan blanco, ya que los escritos existentes se refieren tan sólo a algunas peculiaridades que le distinguen de aquél.

El autor nos ofrece sus profundos conocimientos y su larga experiencia tanto en laboratorio como y su larga exicación.

La parte descriptiva del libro se complementa con gráficos, diagramas y fotografias de gran utilidad, destinados a conseguir la aplicación apropiada de este aglomerante.

Un volumen encuadernado en cartoné policerado, de $17,4 \times 24,3 \mathrm{~cm}$, compuesto de 395 páginas, numerosas figuras, tablas y ábacos.

Precios: España, 1.700 ptas.; extranjero, \$ 34.

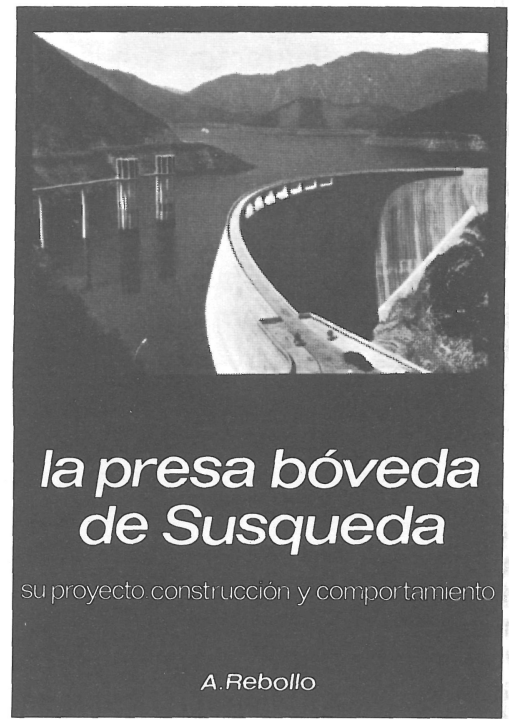

La presa bóveda de Susqueda

A. Rebollo,

Dr. Ingeniero de Caminos

El esfuerzo del constructor de presas se sitúa, por su pretensión de perennidad, a contracorriente rizada por lo fungible. Pueden evocarse las 10.000 grandes. presas en funcionamiento o en construcción grandes. presas en funcionamiento o en construcción gerontológicos para mantener y perfeccionar su gerontologicos para mantener y perfeccionar su perennidad. En la medida en que todas nuevas obras, grandes o pequeñas, son portadoras de riesgos ecológicos $y$, a veces, catastróficos, que aumentan con el envejecimiento, la gerontologia de las presas es todo un emplazo. La acción adelantada de Arturo Rebollo en este terreno marca un camino a seguir para todos los que aman su propia obra con la devoción paternal que él ha puesto en Susqueda.

Un volumen encuadernado en cartoné plastificado con lomo de tela, de $18 \times 24,5 \mathrm{~cm}$, compuesto de 408 páginas, 330 figuras y fotografias y 39 tablas.

Precios: 1.700 ptas.; extranjero, \$ USA 24.00. 